Article

\title{
Structural Characteristics and Non-Linear Optical Behaviour of a 2-Hydroxynicotinate-Containing Zinc-Based Metal-Organic Framework
}

\section{Shruti Mendiratta ${ }^{1}$, Cheng-Hua Lee ${ }^{1}$, Sih-Ying Lee ${ }^{1,2}$, Ya-Chuan Kao ${ }^{1}$, Bor-Chen Chang ${ }^{3}$, Yih-Hsing Lo ${ }^{2}$ and Kuang-Lieh Lu ${ }^{1, *}$}

1 Institute of Chemistry, Academia Sinica, Taipei 115, Taiwan;

E-Mails: shruti.mendiratta@gmail.com (S.M.); d9722102@mail.ntust.edu.tw (C.-H.L.); pokesp@gmail.com (S.-Y.L.); ap123280510@gmail.com (Y.-C.K.)

2 Department of Applied Physics and Chemistry, University of Taipei, Taipei 106, Taiwan; E-Mail: yhlo@utaipei.edu.tw

3 Department of Chemistry, National Central University, Taoyuan 320, Taiwan; E-Mail: bchang@ncu.edu.tw

* Author to whom correspondence should be addressed; E-Mail: kllu@gate.sinica.edu.tw; Tel.: +886-2-2789-8518; Fax: +886-2-2783-1237.

Academic Editor: Dong-Sheng Li

Received: 30 March 2015 / Accepted: 12 May 2015 / Published: 18 May 2015

\begin{abstract}
Materials with non-linear optical (NLO) properties play an important role in the construction of electronic devices for optical communications, optical data processing and data storage. With this aim in mind, a $\mathrm{Zn}$ (II)-based metal-organic framework $\left\{\left[\mathrm{Zn}_{2} \text { (nica) }{ }_{2}(\text { bpy })_{1.5}\left(\mathrm{H}_{2} \mathrm{O}\right)\right] \cdot 0.5 \text { (bpy) } \cdot 3 \mathrm{H}_{2} \mathrm{O}\right\}_{\mathrm{n}}$ (1), was synthesized using 4,4'-bipyridine (bpy) and a potentially bidentate ligand, 2-hydroxynicotinic acid ( $\mathrm{H}_{2}$ nica) with a salicylate binding moiety. A single-crystal X-ray diffraction analysis revealed that compound $\mathbf{1}$ crystallized in the orthorhombic space group $F d d 2$ and was composed of a three dimensional porous framework. Since $F d d 2$ belonged to a class of non-centrosymmetric space groups, we therefore investigated the non-linear optical behaviour of compound $\mathbf{1}$. Photoluminescence studies revealed that compound $\mathbf{1}$ exhibited a blue light emission with a maxima at $457 \mathrm{~nm}$.
\end{abstract}


Keywords: 4,4'-bipyridine; emission; 2-hydroxynicotinic acid; metal-organic framework; non-linear optics

\section{Introduction}

Metal-organic frameworks (MOFs) have gained considerable attention as a new type of multifunctional materials owing to their numerous real and potential applications in gas sorption, storage, chemical and biological detection, medical imaging and light emitting devices [1-7]. These hybrid materials take advantage of the properties of both traditional inorganic and organic materials and comprise novel functional materials with a degree of structural predictability [8]. Further, a non-centrosymmetric organization of molecular building blocks is essential for a bulk material to exhibit second order non-linear optical (NLO) effects and the construction of such acentric MOFs presents a great challenge to conventional synthetic strategies [9-11]. Non-linear optics as a bridge linking photons and electrons have gained interest due to their extensive applications in harmonic generation, amplitude and phase modulation, signal transmission, processing and storage, and promise to have a great impact on information technologies, in which NLO materials play important roles [12,13].

The 2-hydroxynicotinic acid ( $\mathrm{H}_{2}$ nica) ligand contains a salicylate binding moiety and can bind to metal ions by different coordination modes, namely, monodentate, bridging, $\mathrm{N}, \mathrm{O}$-chelation (involving the pyridine nitrogen and the oxygen in position-2, with the formation of a four membered chelate ring) and $O, O$-chelation (involving the carboxylate group and the oxygen in position-2, resulting in a six membered chelate ring). In addition, $\mathrm{H}_{2}$ nica is characterized by keto-enol tautomerism (Scheme 1), since the labile hydrogen atom of the $\mathrm{OH}$ group is in very close proximity to the basic $\mathrm{N}$ atom and can be easily attached to it. In the solid state the ketone form is favored as it is stabilized by intramolecular hydrogen bonding between the $\mathrm{COOH}$ and $\mathrm{C}=\mathrm{O}$ groups.

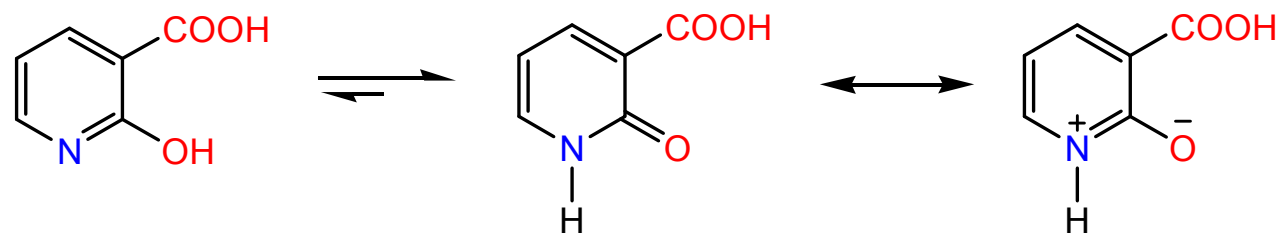

Scheme 1. Keto-enol tautomerism in $\mathrm{H}_{2}$ nica.

As part of our research on functional crystalline materials [14-18], we envisaged that the $\mathrm{H}_{2}$ nica ligand may be suitable for use in the construction of NLO metal-organic frameworks due to its structural characteristics. Herein we report on an interesting Zn-based coordinated framework $\left\{\left[\mathrm{Zn}_{2} \text { (nica) }\right)_{2}(\text { bpy })_{1.5}\left(\mathrm{H}_{2} \mathrm{O}\right)\right] \cdot 0.5($ bpy $\left.) \cdot 3 \mathrm{H}_{2} \mathrm{O}\right\}_{n}$ (1, bpy $=4,4^{\prime}$-bipyridine). Importantly, compound $\mathbf{1}$ features: (1) preparation through a one-step self-assembly process; (2) a three dimensional porous MOF framework; (3) blue light emission with a maxima at $457 \mathrm{~nm}$; (4) it crystallizes in the crystal class $m m 2$ (point group $C_{2 v}$ ), with an orthorhombic non-centrosymmetric space group ( $F d d 2$ ); (5) a modest second harmonic generation (SHG) intensity in comparison to $\mathrm{SiO}_{2}$. To the best of our knowledge, such non-linear optical behaviour and luminescence properties of such a coordination compound have never been previously explored. 


\section{Results and Discussion}

\subsection{Synthesis}

Compound 1 was synthesized from a mixture of $\mathrm{Zn}\left(\mathrm{NO}_{3}\right)_{2} \cdot 6 \mathrm{H}_{2} \mathrm{O}, \mathrm{H}_{2}$ nica and bpy via a single-step, self-organization process (Scheme 2). The FTIR spectrum of 1 showed the presence of pyridine and carboxylate groups, implying that the nica ${ }^{2-}$ and bpy ligands have coordinated to the metal centers. The appropriate choice of an organic ligand with a specific geometry and heteroatoms is crucial for the success of the self-assembly reaction. The $\mathrm{H}_{2}$ nica molecule, despite its simplicity, is a very versatile bridging ligand. The chelating and partially-deprotonated nature of this ligand generates multiple coordination modes [19,20]. Scheme 3 shows the possible coordination modes of the fully deprotonated nica $^{2-}$ ligand. More importantly, a non-centrosymmetric geometry of the final product can be generated by this ligand, including $\mathrm{N}, \mathrm{O}$-chelation (through the pyridine nitrogen and the deprotonated phenolate oxygen, forming a four membered chelate ring) as in modes $\mathrm{G}$ and $\mathrm{H}$, and $O, O$-chelation (through the carboxylate group and the deprotonated phenolate oxygen, forming a six membered chelate ring, salicylate type chelation) as in modes $\mathrm{A}$ to $\mathrm{H}$.

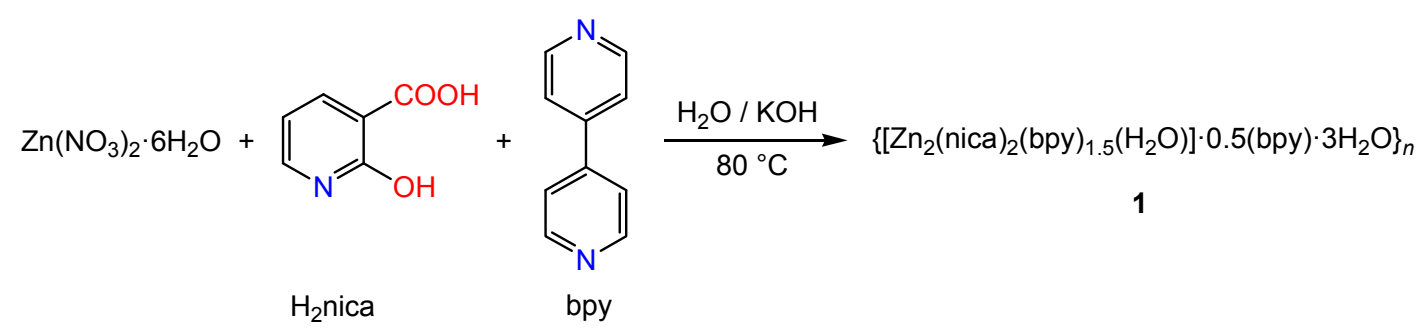

Scheme 2. The synthesis of compound 1.<smiles>[M]OC(=O)c1ccc[n+]([M])c1O[M]</smiles>

(A)<smiles>[M]OC(O[M])c1cccn([M])c1=O</smiles>

(E)<smiles>[M]OC(=O)c1c(C(O[M])O[M])ccc[n+]1[M]</smiles>

(B)<smiles>[M]OC(O[M])c1cccn([M])c1=O</smiles>

$(\mathrm{F})$<smiles>[M]Oc1c(C(O[M])O[M])ccc[n+]1[M]</smiles>

(C)<smiles>[M]OC(=O)c1cccn2nc(O[M])cc12</smiles>

(G)<smiles></smiles>

(D)<smiles>[M]OC(OC)c1cccn2cccc12</smiles>

$(\mathrm{H})$

Scheme 3. Possible coordination modes of the nica ${ }^{2-}$ ligand.

\subsection{Crystal Structure}

A single-crystal X-ray diffraction analysis showed that compound $\mathbf{1}$ crystallized in the crystal class $m m 2$ (point group $C_{2 v}$ ), with an orthorhombic non-centrosymmetric space group $(F d d 2)$. The asymmetric unit of 1 consisted of two crystallographically distinct metal centers, two nica ${ }^{2-}$ ligands, one and a half 
bpy ligands and one coordinated water molecule. The possible coordination modes of the nica ${ }^{2-}$ ligand are shown in Scheme 3 and mode $H$ was observed in the structure of $\mathbf{1}$. As shown in Figure 1b,c, the $\mathrm{Zn} 1$ (II) center adopts a six-coordinated $\left\{\mathrm{ZnN}_{2} \mathrm{O}_{4}\right\}$ octahedral geometry surrounded by four oxygens (O1, $\mathrm{O} 2$ and $\mathrm{O} 4, \mathrm{O} 5$ ) of two different nica ${ }^{2-}$ ligands in a chelating mode and two nitrogens (N4 and N5) of two different bpy ligands. On the other hand, $\mathrm{Zn} 2$ (II) center displays a six-coordinated $\left\{\mathrm{ZnN}_{3} \mathrm{O}_{3}\right\}$ distorted octahedral geometry constructed by two nitrogens and two oxygens (O1, N1 and O4, N2) from the nica ${ }^{2-}$ ligands in a chelating mode, one nitrogens (N3) of bpy ligand, and one of the coordination water (O7). The Zn-N bond lengths are in the range of 2.038(2)-2.277(2) $\AA$, and the Zn-O bond lengths are in the range of 1.990(2)-2.347(2) $\AA$. The crystallographic data and structural refinements for 1 are summarized in Table 1 and the corresponding bond lengths and bond angles are listed in Tables S1 and S2 (Supplementary Materials).

(a)

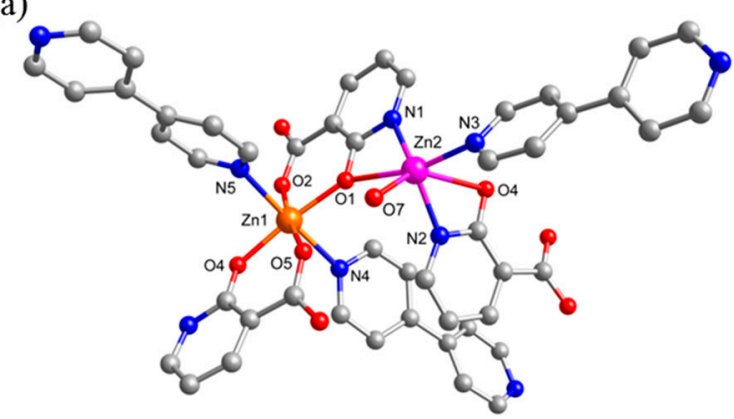

(b)

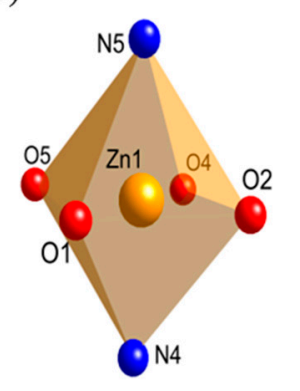

(c)

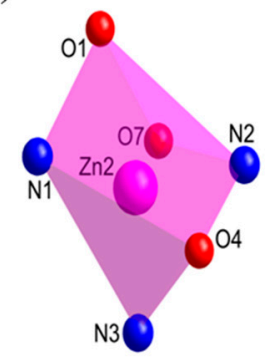

Figure 1. (a) The asymmetric unit of 1; (b) view of the local coordination environment of $\mathrm{Zn} 1$ center; (c) local coordination environment of $\mathrm{Zn} 2$ center [symmetry code: (i): $(-0.25+\mathrm{x}$, $0.25-\mathrm{y},-0.25+\mathrm{z})$; (ii): $(0.25-\mathrm{x}, 0.25+\mathrm{y}, 0.25+\mathrm{z})]$.

Table 1. Summary of crystal data and refinement results.

\begin{tabular}{cc}
\hline Compound & $\mathbf{1}$ \\
\hline chemical formula & $\mathrm{C}_{32} \mathrm{H}_{30} \mathrm{~N}_{6} \mathrm{O}_{10} \mathrm{Zn}_{2}$ \\
formula weight & 789.36 \\
crystal system & Orthorhombic \\
space group & $F d d 2$ \\
temperature & $100.0(2)$ \\
$a(\AA)$ & $26.630(5)$ \\
$b(\AA)$ & $35.928(7)$ \\
$c(\AA)$ & $13.001(3)$ \\
$V\left(\AA^{3}\right)$ & $12,439(4)$ \\
$\mathrm{Z}$ & 16 \\
$D_{\text {calcd }}\left(\mathrm{g} / \mathrm{cm}^{3}\right)$ & 1.686 \\
$\theta$ range $/\left({ }^{\circ}\right)$ & $1.83-27.10$ \\
$\left.\mu(\mathrm{mm})^{-1}\right)$ & 1.614 \\
$F(000)$ & 6464 \\
reflns collected & 6515 \\
unique reflns & 6776 \\
\hline
\end{tabular}


Table 1. Cont.

\begin{tabular}{cc}
\hline Compound & $\mathbf{1}$ \\
\hline parameters & 451 \\
$R_{\text {int }}$ & 0.0426 \\
$R_{1}, w R_{2}{ }^{\mathrm{a}}(I>2 \sigma(I))$ & $0.0211,0.0492$ \\
$R_{1}, w R_{2}{ }^{\mathrm{a}}($ all data $)$ & $0.0227,0.0497$ \\
GOF & 1.071 \\
${ }^{\mathrm{a}} R_{1}=\Sigma|| F_{0}|-| F_{\mathrm{c}}|| \Sigma\left|F_{0}\right| ; w R_{2}=\left[\Sigma w\left(F_{0}{ }^{2}-F_{\mathrm{c}}{ }^{2} / \Sigma \mathrm{w}\left(F_{0}\right)^{2}\right]^{1 / 2}\right.$
\end{tabular}

In the structure, a zig-zag chain formed through the chelation of nica ${ }^{2-}$ ligands with $\mathrm{Zn}$ (II) ions in the $\mathrm{N}, \mathrm{O}$ and $\mathrm{O}, \mathrm{O}$-chelation modes can be observed along the $c$ axis (Figure 2a). Further, the bpy ligands extend the one dimensional structure to a three dimensional porous framework by coordination with the neighbouring one dimensional chains (Figure 2b). Free guest molecules such as water and 4,4'-bipyridine occupy the voids in the framework (Figure 2c). Coordinated water molecules show strong hydrogen bonding interactions with the carboxylate group of nica ${ }^{2-}$ ligand and guest water molecules (Table S3 and Figure S1, Supplementary Materials). In addition to the hydrogen bonding interactions, strong $\mathrm{C}-\mathrm{H} \cdots \pi$ (purple and blue dashed lines) and relatively weaker $\pi-\pi$ (green dashed line) interactions can also be seen between the free bpy ligands and the coordinated bpy ligands (Figure S1, Supplementary Materials). Importantly, compound 1 crystallizes in the non-centrosymmetric space group $F d d 2$ and its polar axis lies along a zig-zag chain. The polarity results from the arrangement of all of the bridging nica $^{2-}$ ligands.

(a)

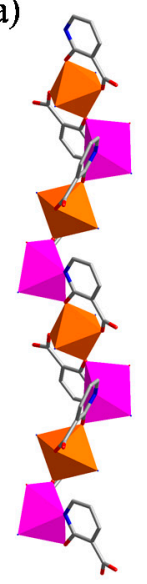

(b)

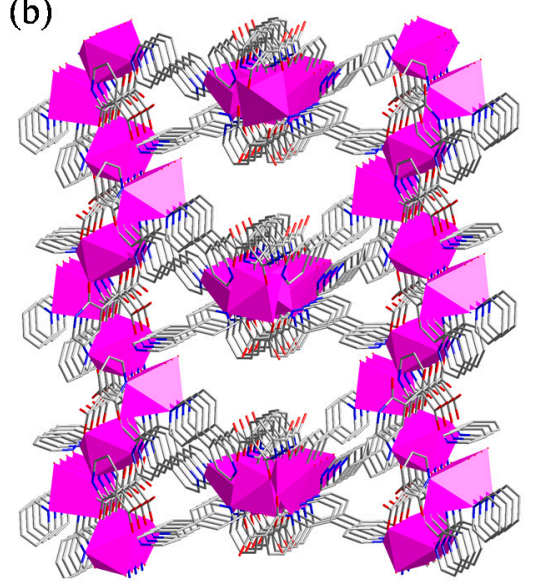

(c)

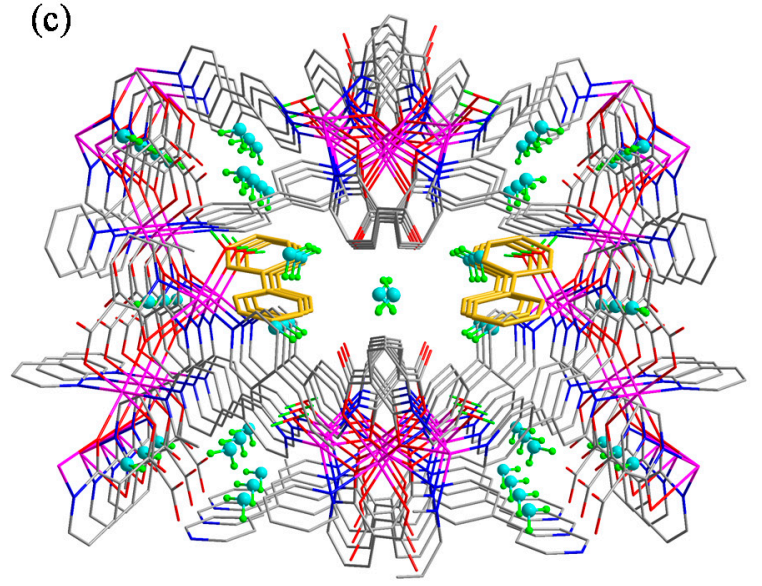

Figure 2. (a) Formation of metal chains in 1 through the coordination of nica ${ }^{2-}$ ligands in a chelating manner; (b) the 3D framework in 1 viewed along the $c$ axis; (c) incorporation of guest molecules such as water and 4,4'-bipyridine.

\subsection{Thermal Stability}

To assess the thermal stability and structural variation as a function of temperature, TGA analyses of a single phase polycrystalline sample were carried out (Figure 3a). Compound $\mathbf{1}$ was found to undergo a weight loss of $5.6 \%$ at a temperature of around $140{ }^{\circ} \mathrm{C}$, corresponding to the loss of guest water 
molecules. The corresponding powder X-ray diffraction pattern of $\mathbf{1}$, agrees well with a simulated pattern (Figure $3 \mathrm{~b}$ ) and the purity of compound was further confirmed by elemental analysis.
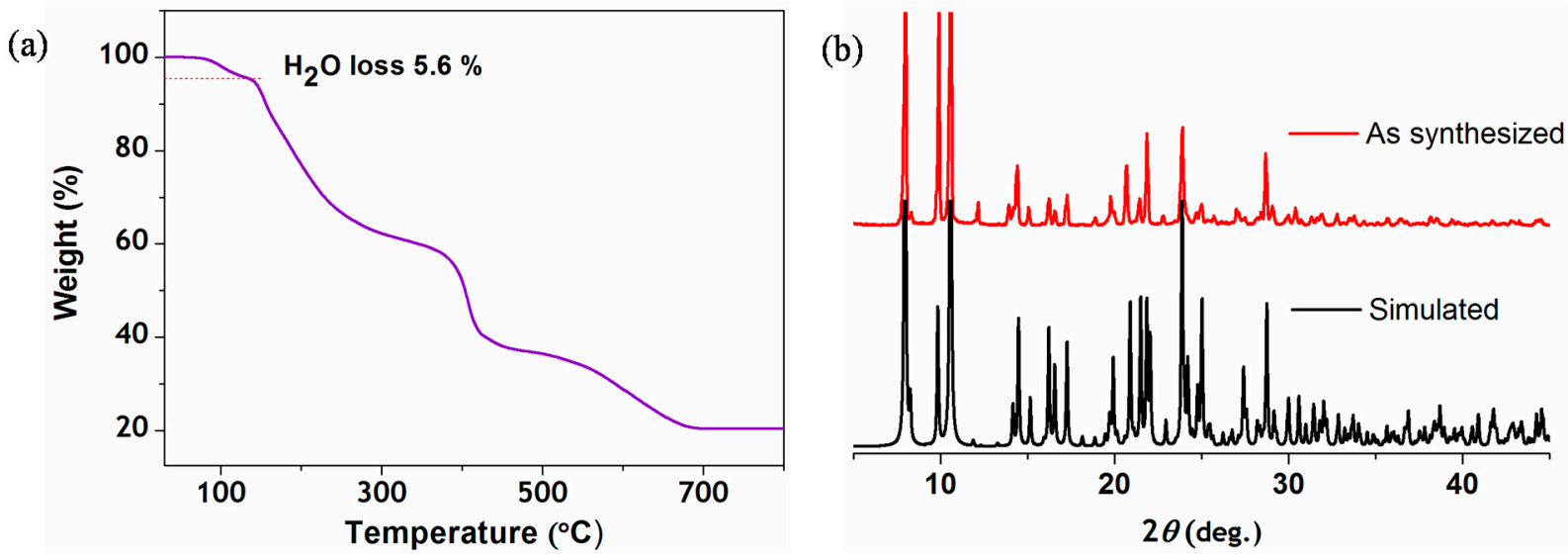

Figure 3. (a) Thermogravimetric plot of compound 1; (b) the corresponding PXRD patterns of compound 1 .

\subsection{Photoluminescence Studies}

The solid-state photoluminescent properties of 1 were investigated at room temperature. An emission spectrum of this compound revealed that, when excited with a wavelength of $397 \mathrm{~nm}$, a blue light emission was observed at around $457 \mathrm{~nm}$ (Figure 4). Compared with the free ligands bpy and $\mathrm{H}_{2}$ nica, the emission peak for 1 was significantly red-shifted. Figure showing the corresponding excitation spectra for ligands and compound 1 has been included as Figure S3 (Supplementary Materials). The emission of compound $\mathbf{1}$ can be attributed to either ligand-to-ligand charge transfer transition (LLCT) or a ligand-to-metal charge transfer transition (LMCT) or a combination of both $[21,22]$.

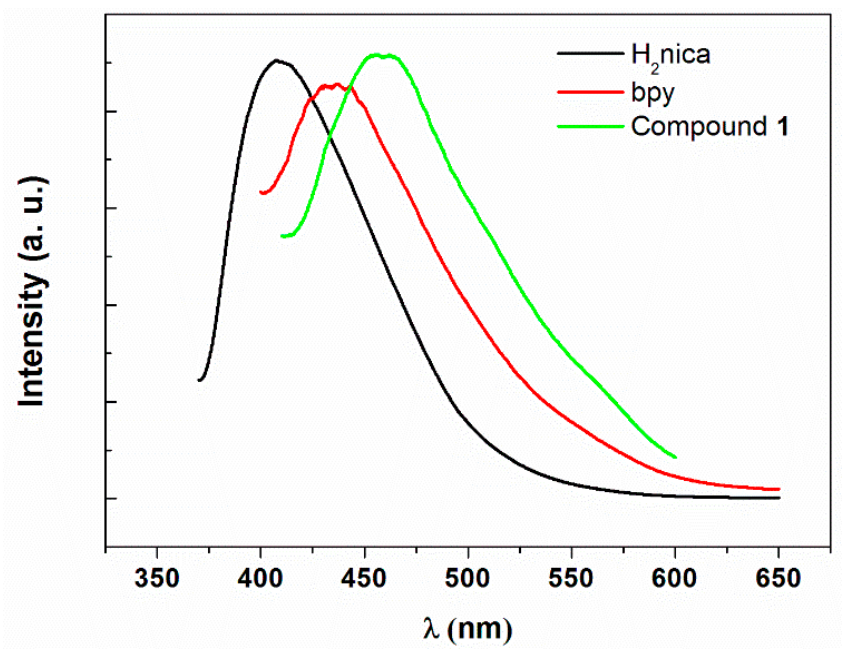

Figure 4. Emission spectra of 1 compared with the ligands.

\subsection{Non-Linear Optical Studies}

A number of Zn-based metal-organic frameworks and Schiff-base complexes have been investigated for their second order NLO properties [23-26]. We recently reported on the preparation of 
multifunctional chiral MOFs displaying low dielectric, luminescent and second order NLO properties [14]. Interestingly, Zeng and co-workers reported the inclusion of polyiodide anions in microporous MOFs and explored the kinetics of the release and recovery of iodine molecules [27]. They probed the effect of polyiodide anions on non-linear optical activity between the as-synthesized sample and the neutral iodine released sample. Inspired by the above studies we envisaged that a versatile ligand such as $\mathrm{H}_{2 n i c a}$ may be suitable for the construction of non-centrosymmetric MOFs.

Second-order non-linear optical effects were examined to confirm the physical properties derived from the assignment of compound 1 to a crystal class $m m 2$ (point group $\mathrm{C}_{2 v}$ ) with an acentric space group ( $F d d 2$ ). To detect the non-linear optical properties, as per the methods recommended by Kurtz and Perry [28], the second harmonic generation (SHG) efficiency was measured on the single crystal of 1 using a laser source (Figure 5). The observed peak appeared at $532 \mathrm{~nm}$ and its SHG intensity was found to be weaker than $\mathrm{SiO}_{2}$. In theory, the SHG intensity $I_{2 \omega}$ from any interface of the crystal in either reflection or transmission geometry is proportional to the square of the NLO coefficient $\chi^{(2)}$ and to the energy of the fundamental frequency beam $I_{\omega}$ [Equation (1)]:

$$
I_{2 \omega}=\frac{32 \pi^{3} \omega^{2} s^{2} \theta_{2 \omega}}{c^{3}}\left|e_{2 \omega} \cdot \chi^{(2)} e_{\omega}^{2}\right|^{2} I_{\omega}^{2} \propto\left(\chi^{(2)}\right)^{2} I_{\omega}^{2}
$$

where $\theta$ is the angle from the surface normal, at which the SHG signal occurs, the vectors $\mathrm{e}_{\omega}$ and $\mathrm{e}_{2 \omega}$ describe the fundamental and the second harmonic light fields at the surface [10,29]. The SHG efficiency depends on various factors such as: the donor-acceptor system in the framework, the extent of non-centrosymmetry in the system, the intensity of the push-pull dipole effect exerted by the ligand and finally the functional groups that are attached to the ligands and the guest molecules that are incorporated in the structure [10,30-34].

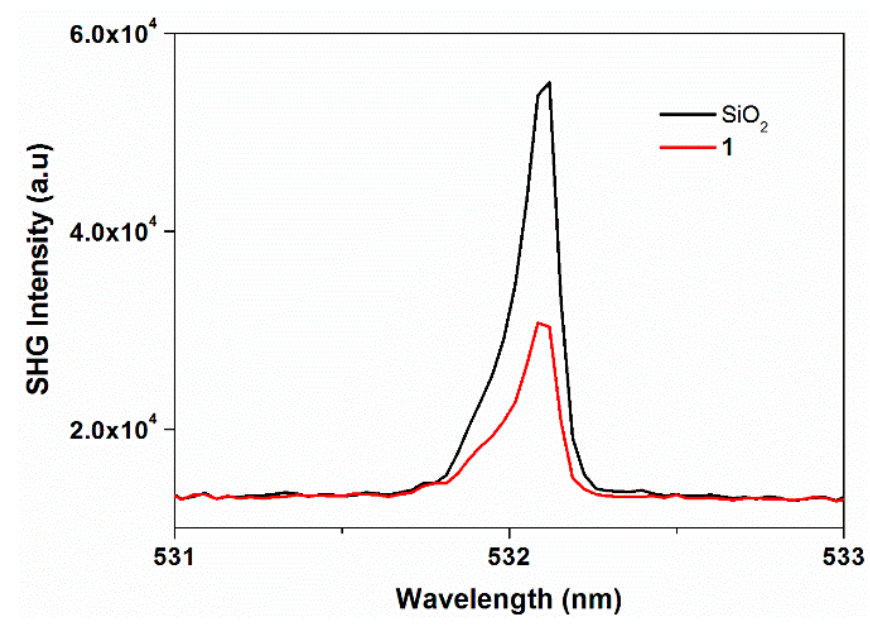

Figure 5. SHG plot of compound 1.

The modest SHG response in the present case can be attributed to the partial cancellation of non-centrosymmetry between the intercrossing zig-zag chains as the dipole moments are cancelled out and partly to the absorption by the crystal in the presence of bpy guest molecules. 


\section{Experimental Section}

\subsection{General Information}

All chemicals were purchased commercially and were used as received without further purification. Diffraction measurements for compound 1 were carried out using a Bruker-Nonius Kappa CCD diffractometer (Bruker, Karlsruhe, Germany) with graphite-monochromated Mo-K $\alpha$ radiation. The structures were solved using direct methods and refined using the SHELXS-2013 [35] program (2013, SHELX, Göttingen, Germany) by full-matrix least squares on $F^{2}$ values. CCDC 1056788 contains the supplementary crystallographic data for this paper. These data can be obtained free of charge via website [36] (or from the CCDC, 12 Union Road, Cambridge CB2 1EZ, UK; Fax: +44-1223-336033; E-mail: deposit@ccdc.cam.ac.uk). Elemental analyses were conducted on a $2400 \mathrm{CHN}$ elemental analyzer (Perkin-Elmer, Waltham, MA, USA). Infrared spectra were recorded in the range of $4000-400 \mathrm{~cm}^{-1}$ on a Perkin-Elmer Paragon 1000 FT-IR spectrophotometer. Thermogravimetric analyses (TGA) were performed under a nitrogen atmosphere with a Perkin-Elmer TGA-7 TG analyser. Powder X-ray diffraction patterns were recorded with a XPert-Pro diffractometer (Philips, Eindhoven, Netherlands) at $40 \mathrm{kV}(30 \mathrm{~mA})$ with $\mathrm{Cu}-\mathrm{K} \alpha(\lambda=1.5406 \AA)$.

\subsection{Synthesis of $\left\{\left[\mathrm{Zn}_{2}(\text { nica })_{2}(\text { bpy })_{1.5}\left(\mathrm{H}_{2} \mathrm{O}\right)\right] \cdot 0.5(\right.$ bpy $\left.) \cdot 3 \mathrm{H}_{2} \mathrm{O}\right\} n$ (1)}

An aqueous solution $(2 \mathrm{~mL})$ of $\mathrm{H}_{2}$ nica $(14.0 \mathrm{mg}, 0.1 \mathrm{mmol})$ and $\mathrm{KOH}(1 \mathrm{M}), 6 \mathrm{~mL}$ aqueous solution of $\mathrm{Zn}\left(\mathrm{NO}_{3}\right)_{2} \cdot 6 \mathrm{H}_{2} \mathrm{O}(29.9 \mathrm{mg}, 0.1 \mathrm{mmol})$ and aqueous solution $(6 \mathrm{~mL})$ of bpy (31.3 mg, $\left.0.2 \mathrm{mmol}\right)$ were mixed together and then heated in the water bath at $80{ }^{\circ} \mathrm{C}$ for three days until dark orange crystals (15.3 mg) were obtained. Yield: 19.4\%. Anal. Calcd (\%) for $\mathrm{C}_{32} \mathrm{H}_{30} \mathrm{~N}_{6} \mathrm{O}_{10} \mathrm{Zn}_{2}: \mathrm{C}, 48.69 ; \mathrm{H}, 3.83$; N, 10.65 . Found: C, 48.63; H, 3.78; N, 10.77. IR (KBr, cm $\left.{ }^{-1}\right): v=3400(\mathrm{~m}), 3176(\mathrm{~m}), 1951(\mathrm{~m}), 1929$ (s), 1603 (vs), 1557 (vs), 1533 (w), 1448 (w), 1481 (vs), 1423 (m), 1408 (s), 1374 (vs), 1253 (s), 1216 (s), 1150 (s), 1096 (m), 1067 (s), $1006(\mathrm{~m}), 991$ (m), 974 (m), 953 (w), 934 (s), 795 (vs), 729 (s), $678(\mathrm{~m}), 660$ (m), $631(\mathrm{vs}), 590(\mathrm{w}), 570(\mathrm{~m}), 542(\mathrm{w}), 496(\mathrm{~s}), 474(\mathrm{~m}) \mathrm{cm}^{-1}$.

\section{Conclusions}

A 3D non-centrosymmetric $\mathrm{Zn}$ (II)-based MOF was successfully synthesized. Compound 1 crystallized in the crystal class $m m 2$ (point group $C_{2 v}$ ), with an orthorhombic non-centrosymmetric space group ( $F d d 2$ ). Although its SHG intensity was found to be modest in comparison to the traditional NLO materials, a possible structure-NLO property relationship is demonstrated. These results prompted us to synthesize MOFs with better NLO properties in the future.

\section{Supplementary Materials}

Supplementary materials can be accessed at: http://www.mdpi.com/1420-3049/20/05/8941/s1.

\section{Acknowledgments}

The authors wish to thank Academia Sinica and Ministry of Science and Technology, Taiwan for financial support. 


\section{Author Contributions}

S.Y. Lee synthesized the compound and acquired the elemental analysis, thermogravimetric, IR and powder X-ray diffraction data. C.H. Lee and Y.C. Kao acquired emission, excitation and single-crystal diffraction data. Non-linear optical data was provided by B.C. Chang. S. Mendiratta wrote the manuscript, which was revised by Y.H. Lo and K.L. Lu.

\section{Conflicts of Interest}

The authors declare no conflict of interest.

\section{References}

1. Sun, C.Y.; Wang, X.L.; Zhang, X.; Qin, C.; Li, P.; Su, Z.M.; Zhu, D.X.; Shan, G.G.; Shao, K.Z.; $\mathrm{Wu}, \mathrm{H}$; et al. Efficient and tunable white-light emission of metal-organic frameworks by iridium-complex encapsulation. Nat. Commun. 2013, 4, doi:10.1038/ncomms3717.

2. Ma, W.; Jiang, Q.; Yu, P.; Yang, L.; Mao, L. Zeolitic imidazolate framework-based electrochemical biosensor for in vivo electrochemical measurements. Anal. Chem. 2013, 85, 7550-7557.

3. Kim, T.K.; Lee, J.H.; Moon, D.; Moon, H.R. Luminescent Li-based metal-organic framework tailored for the selective detection of explosive nitroaromatic compounds: Direct observation of interaction sites. Inorg. Chem. 2013, 52, 589-595.

4. Yang, S.; Lin, X.; Lewis, W.; Suyetin, M.; Bichoutskaia, E.; Parker, J.E.; Tang, C.C.; Allan, D.R.; Rizkallah, P.J.; Hubberstey, P.; et al. A partially interpenetrated metal-organic framework for selective hysteretic sorption of carbon dioxide. Nat. Mater. 2012, 11, 710-716.

5. Taylor, K.M.L.; Rieter, W.J.; Lin, W. Manganese-based nanoscale metal-organic frameworks for magnetic resonance imaging. J. Am. Chem. Soc. 2008, 130, 14358-14359.

6. Kitagawa, S.; Kitaura, R.; Noro, S. Functional porous coordination polymers. Angew. Chem. Int. Ed. 2004, 43, 2334-2375.

7. Luo, T.T.; Wu, H.C.; Jao, Y.C.; Huang, S.M.; Tseng, T.W.; Wen, Y.S.; Lee, G.H.; Peng, S.M.; Lu, K.L. Self-assembled arrays of single-walled metal-organic nanotubes. Angew. Chem. Int. Ed. 2009, 48, 9461-9464.

8. Jones, J.T.A.; Hasell, T.; Wu, X.; Bacsa, J.; Jelfs, K.E.; Schmidtmann, M.; Chong, S.Y.; Adams, D.J.; Trewin, A.; Schiffman, F.; et al. Modular and predictable assembly of porous organic molecular crystals. Nature 2011, 474, 367-371.

9. Li, L.; Zhang, S.; Han, L.; Sun, Z.; Luo, J.; Hong, M. A non-centrosymmetric dual-emissive metal-organic framework with distinct nonlinear optical and tunable photoluminescence properties. Cryst. Growth Des. 2013, 13, 106-110.

10. Yu, J.; Cui, Y.; Wu, C.; Yang, Y.; Wang, Z.; O’Keeffe, M.; Chen, B.; Qian, G. Second-order nonlinear optical activity induced by ordered dipolar chromophores confined in the pores of an anionic metal-organic framework. Angew. Chem. Int. Ed. 2012, 51, 10542-10545.

11. Allendorf, M.D.; Schwartzberg, A.; Stavila, V.; Talin, A.A. A roadmap to implementing metal-organic frameworks in electronic devices: Challenges and critical directions. Chem. Eur. J. 2011, 17, 11372-11388. 
12. Agranovich, V.M.; Gartstein, Y.N.; Litinskaya, M. Hybrid resonant organic-inorganic nanostructures for optoelectronic applications. Chem. Rev. 2011, 111, 5179-5214.

13. Delaire, J.A.; Nakatani, K. Linear and nonlinear optical properties of photochromic molecules and materials. Chem. Rev. 2000, 100, 1817-1846.

14. Mendiratta, S.; Usman, M.; Luo, T.T.; Chang, B.C.; Lee, S.F.; Lin, Y.C.; Lu, K.L. Anion-controlled dielectric behavior of homochiral tryptophan-based metal-organic frameworks. Cryst. Growth Des. 2014, 14, 1572-1579.

15. Mendiratta, S.; Usman, M.; Luo, T.T.; Lee, S.F.; Lin, Y.C.; Lu, K.L. Guest dependent dielectric properties of nickel(II)-based supramolecular networks. Cryst. Eng. Comm 2014, 16, 6309-6315.

16. Mendiratta, S.; Usman, M.; Tseng, T.W.; Luo, T.T.; Lee, S.F.; Zhao, L.; Wu, M.K.; Lee, M.M.; Sun, S.S.; Lin, Y.C.; Lu, K.L. Low dielectric behavior of a robust, guest-free magnesium(II)-organic framework: A potential application of an alkaline-earth metal compound. Eur. J. Inorg. Chem. 2015, 1669-1674.

17. Usman, M.; Lee, C.H.; Hung, D.S.; Lee, S.F.; Wang, C.C.; Luo, T.T.; Zhao, L.; Wu, M.K.; Lu, K.L. Intrinsic low dielectric behaviour of a highly thermally stable Sr-based metal-organic framework for interlayer dielectric materials. J. Mater. Chem. C 2014, 2, 3762-3768.

18. Usman, M.; Mendiratta, S.; Lu, K.L. Metal-organic frameworks: New interlayer dielectric materials. ChemElectroChem 2015, doi:10.1002/celc.201402456.

19. Long, S.; Zhou, P.; Theiss, K.L.; Siegler, M.A.; Li, T. Solid-state identity of 2-hydroxynicotinic acid and its polymorphism. CrystEngComm 2015, doi:10.1039/C4CE02290D.

20. Quintal, S.M.O.; Nogueira, H.I.S.; Félix, V.; Drew, M.G.B. Coordination modes of 2-hydroxynicotinic acid in second- and third-row transition metal complexes. Polyhedron 2002, 21, 2783-2791.

21. Zhang, L.Y.; Liu, G.F.; Zheng, S.L.; Ye, B.H.; Zhang, X.M.; Chen, X.M. Helical ribbons of cadmium(II) and zinc(II) dicarboxylates with bipyridyl-like chelates - Syntheses, crystal structures and photoluminescence. Eur. J. Inorg. Chem. 2003, 2003, 2965-2971.

22. Bertoncello, R.; Bettinelli, M.; Casarin, M.; Gulino, A.; Tondello, E.; Vittadini, A. Hexakis(acetato)oxotetrazinc, a well-tailored molecular model of zinc oxide. An experimental and theoretical investigation of the electronic structure of $\mathrm{Zn}_{4} \mathrm{O}$ (acetate) 6 and $\mathrm{ZnO}$ by means of $\mathrm{UV}$ and X-ray photoelectron spectroscopies and first principle local density molecular cluster calculations. Inorg. Chem. 1992, 31, 1558-1565.

23. Tessore, F.; Roberto, D.; Ugo, R.; Mussini, P.; Quici, S.; Ledoux-Rak, I.; Zyss, J. Large, concentration-dependent enhancement of the quadratic hyperpolarizability of $\left[\mathrm{Zn}\left(\mathrm{CH}_{3} \mathrm{CO}_{2}\right)_{2}(\mathrm{~L})_{2}\right]$ in $\mathrm{CHCl}_{3}$ on substitution of acetate by triflate. Angew. Chem. Int. Ed. 2003, 42, 456-459.

24. Dragonetti, C.; Balordi, M.; Colombo, A.; Roberto, D.; Ugo, R.; Fortunati, I.; Garbin, E.; Ferrante, C.; Bozio, R.; Abbotto, A.; et al. Two-photon absorption properties of $\mathrm{Zn}(\mathrm{II})$ complexes: Unexpected large TPA cross section of dipolar [ $\mathrm{ZnY}_{2}\left(4,4^{\prime}\right.$-bis(para-di-n-butylaminostyryl)-2,2'bipyridine)] ( $\left.\mathrm{Y}=\mathrm{Cl}, \mathrm{CF}_{3} \mathrm{CO}_{2}\right)$. Chem. Phys. Lett. 2009, 475, 245-249.

25. Oliveri, I.P.; Failla, S.; Colombo, A.; Dragonetti, C.; Righetto, S.; Bella, S.D. Synthesis, characterization, optical absorption/fluorescence spectroscopy, and second-order nonlinear optical properties of aggregate molecular architectures of unsymmetrical Schiff-base zinc(II) complexes. Dalton. Trans. 2014, 43, 2168-2175. 
26. Yin, Z.; Zhou, Y.L.; Zeng, M.H.; Kurmooc, M. The concept of mixed organic ligands in metal-organic frameworks: Design, tuning and functions. Dalton. Trans. 2015, 44, 5258-5275.

27. Yin, Z.; Wang, Q.X.; Zeng, M.H. Iodine release and recovery, influence of polyiodide anions on electrical conductivity and nonlinear optical activity in an interdigitated and interpenetrated bipillared-bilayer metal-organic framework. J. Am. Chem. Soc. 2012, 134, 4857-4863.

28. Kurtz, S.K.; Perry, T.T. A powder technique for the evaluation of nonlinear optical materials. J. Appl. Phys. 1968, 39, 3798-3813.

29. Corn, R.M.; Higgins, D.A. Optical second harmonic generation as a probe of surface chemistry. Chem. Rev. 1994, 94, 107-125.

30. Cariati, E.; Dragonetti, C.; Lucenti, E.; Nisic, F.; Righetto, S.; Roberto, D.; Tordin, E. An acido-triggered reversible luminescent and nonlinear optical switch based on a substituted styrylpyridine: Efish measurements as an unusual method to reveal a protonation-deprotonation NLO contrast. Chem. Commun. 2014, 50, 1608-1610.

31. Zhou, W.W.; Chen, J.T.; Xu, G.; Wang, M.S.; Zou, J.P.; Long, X.F.; Wang, G.J.; Guo, G.C.; Huang, J.S. Nonlinear optical and ferroelectric properties of a 3-D Cd(II) triazolate complex with a novel $\left(6^{3}\right)_{2}\left(6^{10} .8^{5}\right)$ topology. Chem. Commun. 2008, 24, 2762-2764.

32. Lin, W.; Evans, O.R.; Xiong, R.G.; Wang, Z. Supramolecular engineering of chiral and acentric 2D networks. Synthesis, structures, and second-order nonlinear optical properties of bis(nicotinato)zinc and bis \{3-[2-(4-pyridyl)ethenyl]benzoato\} cadmium. J. Am. Chem. Soc. 1998, 120, 13272-13273.

33. Cariati, E.; Roberto, D.; Ugo, R.; Ford, P.C.; Galli, S.; Sironi, A. X-ray structures and emissive and second-order nonlinear optical properties of two inorganic-organic polymeric adducts of $\mathrm{CuI}$ with 4-acetylpyridine. The role of both "Intrastrand" charge transfers and structural motifs on the nonlinear optical response of $\mathrm{Cu}(\mathrm{I})$ polymeric adducts with pseudoaromatic $\eta^{1}$-nitrogen donor ligands. Chem. Mater. 2002, 14, 5116-5123.

34. Hu, S.; Zou, H.H.; Zeng, M.H.; Wang, Q.X.; Liang, H. Molecular packing variation of crimpled 2D Layers and 3D uncommon $6^{5} .8$ topology: effect of ligand on the construction of metal-quinoline-6-carboxylate polymers. Cryst. Growth Des. 2008, 8, 2346-2351.

35. Sheldrick, G.M. A short history of SHELX. Acta Crystallogr. A 2008, 64, 112-122.

36. Cambridge Crystallographic Data Centre. Available online: http:/www.ccdc.cam.ac.uk/conts/retrieving.html (accessed on 30 March 2015).

Sample Availability: Samples of compound $\left\{\left[\mathrm{Zn}_{2}(\text { nica })_{2}(\text { bpy })_{1.5}\left(\mathrm{H}_{2} \mathrm{O}\right)\right] \cdot 0.5(\text { bpy }) \cdot 3 \mathrm{H}_{2} \mathrm{O}\right\}_{\mathrm{n}}$ (1) are available from the authors.

(C) 2015 by the authors; licensee MDPI, Basel, Switzerland. This article is an open access article distributed under the terms and conditions of the Creative Commons Attribution license (http://creativecommons.org/licenses/by/4.0/). 